\title{
Design and Development of a Protective Face Mask to Mitigate Community Spread and Prevent Wearer Infection from COVID-19 Using Design Thinking
}

\author{
DAVID BROOKSTEIN, SCD ${ }^{1}$ \\ ${ }^{1}$ Department of Mechanical Engineering, Temple University \\ Correspondence: david.brookstein@temple.edu (David Brookstein)
}

\begin{abstract}
Relatively early during the start of the COVID-19 pandemic it was widely recognized that community spread could be mitigated by the widespread wearing of cloth face masks since it was assumed that cloth could filter virus containing aerosols and droplets and, as such, minimize their transmission from an infected person. However, at first, face masks were difficult to procure commercially and, in view of that, the CDC discouraged the use of available face masks (such as N95 respirators and surgical masks) for the general public since this might cause shortages for healthcare workers. Subsequently, the CDC suggested that homemade cloth masks, without filters, should be used by the general public since these were considered ineffective for protecting healthcare workers from becoming infected. Filters though, substantially increase the effectiveness of preventing exposure to virus containing aerosols and droplets. Using the concepts of design thinking, innovative and effective protective face masks with filter materials were designed and developed by the author using readily available commercial materials. The uniquely designed protective face mask would afford the general public a way to mitigate community spread of the virus. Recently, the CDC now recognizes that face masks, including filters, will also protect the wearer from infection by persons who are infected. The author has started and will continue to investigate new and commercially available protective face masks as they come into the market.
\end{abstract}

\section{Introduction}

Protective cloth face masks first found widespread use during the 1918-19 influenza pandemic. While they were commonly worn in operating theaters, they soon became mandatory for police forces, medical workers, and even residents in some U.S. cities. In cities like San Francisco, the decline in deaths from influenza was partly attributed to the mandatory mask-wearing policies and soon it was recognized that they protected the wearer against infection. ${ }^{1}$

The University of Minnesota Center for Infectious Research and Policy reported that while the first U.S. fatality from the pandemic coronavirus was assumed to be in the Seattle area on February 28, 2020 
postmortem testing on decedents from February 6 and February 17 confirmed that COVID-19 was spreading in the San Francisco Bay area weeks earlier than previously thought. ${ }^{2}$

On the same day public health officials announced the first death in the United States from COVID-19, U. S. Surgeon General Jerome Adams ordered Americans to 'STOP BUYING MASKS!' in an all-caps message on Twitter, claiming they are "NOT effective in preventing [the] general public from catching coronavirus" and will deplete mask supplies for healthcare providers. ${ }^{3}$ (emphases added) On March 8, 2020 Dr. Anthony Fauci, director of the National Institute of Allergy and Infectious Diseases, stated during an interview with CBS 60 MINUTES, that "there's no reason to be walking around with a mask," though added he's not "against masks," but worried about health care providers and sick people "needing them," and said masks can lead to "unintended consequences" such as people touching their face when they fiddle with their mask. ${ }^{4}$

On April 13, 2020 the U.S. Centers for Disease Control and Prevention (CDC) recommended that all people wear at least a homemade cloth face covering in public settings where other social distancing measures are difficult to maintain (e.g., grocery stores and pharmacies), especially in areas of significant community-based transmission. This recommendation was based on CDC recent studies, at that time, that a significant portion of individuals with coronavirus lacked symptoms ("asymptomatic") and that even those who eventually develop symptoms ("pre-symptomatic") can transmit the virus to others before showing symptoms. This meant that the virus could spread between people interacting in close proximity_for example, speaking, coughing, or sneezing — even if those people are not exhibiting symptoms. ${ }^{5}$ The CDC also included a link to a YouTube video where U.S. Surgeon General Jerome Adams describes how to make a homemade cloth mask from fabrics such as those found in knitted Tshirts. ${ }^{6}$ The CDC recommended using either a tightly woven cotton fabric such as quilting fabric or cotton sheets or a knit jersey cotton T-shirt fabric.

Figure 1. Typical drawings of tightly woven cotton fabric, loosely woven fabric and cotton knit jersey T-shirt fabric

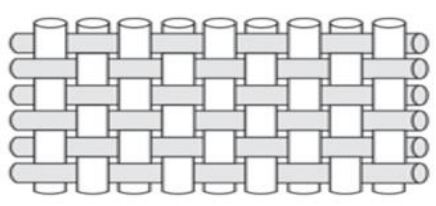

Tightly Woven Fabric

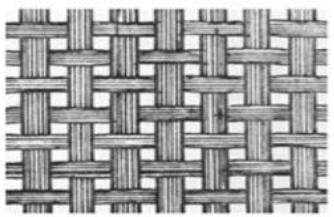

Loosely Woven Fabric

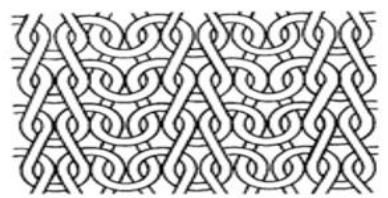

Jersey knit T-Shirt fabric

A study of the efficacy of a homemade cloth mask was published prior to the current pandemic. Public health researchers in the U.K. published a paper titled "Testing the Efficacy of Homemade Masks: Would They Protect in an Influenza Pandemic?"7 They concluded that "improvised bomemade face masks [made from common textile fabrics such as jersey knit T-shirt fabrics] may be used to belp protect those who could potentially, for example, be at occupational risk from close or frequent contact with symptomatic patients. However, these masks would provide the wearers little protection from microorganisms from others persons who are infected with respiratory diseases. As a result, we would not recommend the use of homemade face masks as a method of reducing transmission of infection from aerosols."

Prior to the April CDC guidance, researchers from the MIT Fluid Dynamics of Disease Transmission Laboratory emphasized that mask efficacy is dependent on "the ability of the mask to trap or alter the bighmomentum gas cloud emission with its pathogenic payload." In other words, masks and other protective equipment must be able to "repeatedly withstand the kind of high-momentum multiphase turbulent gas cloud that may be ejected during a sneeze or a cough and the exposure from them." At that time, surgical masks and N95 respirators were not tested for these kinds of respiratory emissions, let alone the simple cloth masks recommended by the CDC. (The designation "N95" denotes that the respirator is designed to filter $95 \%$ of all particles that are at least $0.3 \mu \mathrm{m}$ in diameter.) 
The April CDC recommendations were not only contradictory with current research, but also with existing knowledge about textile design and airborne disease transmission.

Textile engineers, such as this author, know that the interstices between the yarns in a tightly woven fabric would be relatively hard to breathe through and, conversely, either both a loosely woven fabric or a jersey knit fabric would be much easier to breathe through. However, the relatively large size of the interstices between the yarns would permit particles, which might include virus containing liquid droplets or aerosols, to be exhaled during both regular breathing and certainly during a sneeze or cough.

In view of the research in the U.K. and at MIT, the April CDC recommendation for a cloth face mask without an effective filter would likely do little to prevent community spread from either a presymptomatic or asymptomatic COVID-19 carrier. Further, there was no apparent evidence that a cloth face mask without an effective filter would prevent a wearer from being infected as a result of aerosol transmission of the virus. Thus, there was an identified need for the development of protective face masks that contained droplet or aerosol blocking filters that would mitigate the transmission of viruses. In view of that need, the "design thinking process" was used by the author to solve this problem and create an efficacious protective face mask from readily available commercial materials.

\section{Design and Development of a Protective Face Mask to Mitigate Community Spread and Wearer Infection from COVID-19 Using Design Thinking}

Design thinking is a framework that enables engineers to progress through a structured design process. ${ }^{9}$ It is a way to frame a strategy, a design approach, and development around the end-user. The framework lends itself well to the development of novel products that meet enduring human needs such as effective protective face masks. Design Thinking consists of 10 progressive steps that can be summarized as identifying needs, clarifying and formulating the problem, and then solving the problem.

1. Identifying Needs

2. Gather information

3. Stakeholder analysis

4. Operational research

5. Hazard analysis

6. Specification creation

7. Creative design

8. Conceptual design

9. Prototype Design

10. Verification
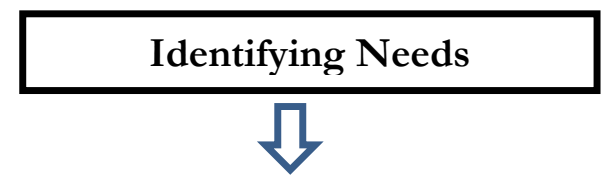

Clarifying and formulating the problem

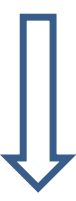

Solving the problem 


\section{Identifying the Need}

While the CDC originally recommended the use of face masks made only from either knitted or woven cloth, this author recognized that, while the face masks might be somewhat effective in mitigating community spread of the COVID-19 virus, face masks would be substantially more effective if they also comprised non-woven filter materials. Unfortunately, in April 2020 the only protective face masks with non-woven filters that were commercially available were N95 respirators and surgical masks which were being rationed to healthcare workers. Those were critical supplies that were needed to be reserved for healthcare workers and other medical first responders, as recommended by current CDC guidance. ${ }^{10}$

\section{Clarifying and Formulating the Problem}

The first step in "Clarifying and formulating the problem" is to gather information. Gathering information consists of first learning about the physical characteristics of aerosols and droplets containing viral particles. Prior to the emergence of the COVID-19 pandemic, researchers at the National Institute for Occupational Safety and Health studied disease transmission by human cough-generated aerosols. ${ }^{11}$ They recognized that aerosol particles expelled during human coughs are a potential pathway for infectious disease transmission. As such, they constructed a human cough simulator that produced a human-like cough in a controlled environment. Using this simulator, they found for a simulated human cough the aerosols had a volume median diameter (VMD) of $3.39 \mu \mathrm{m}$. The plot shows the mean of eight experiments. Error bars show the standard deviation of the measurements.

Figure 2: Volume-based size distribution (VMD) of the simulated cough aerosol using the Aeroneb nebulizer.

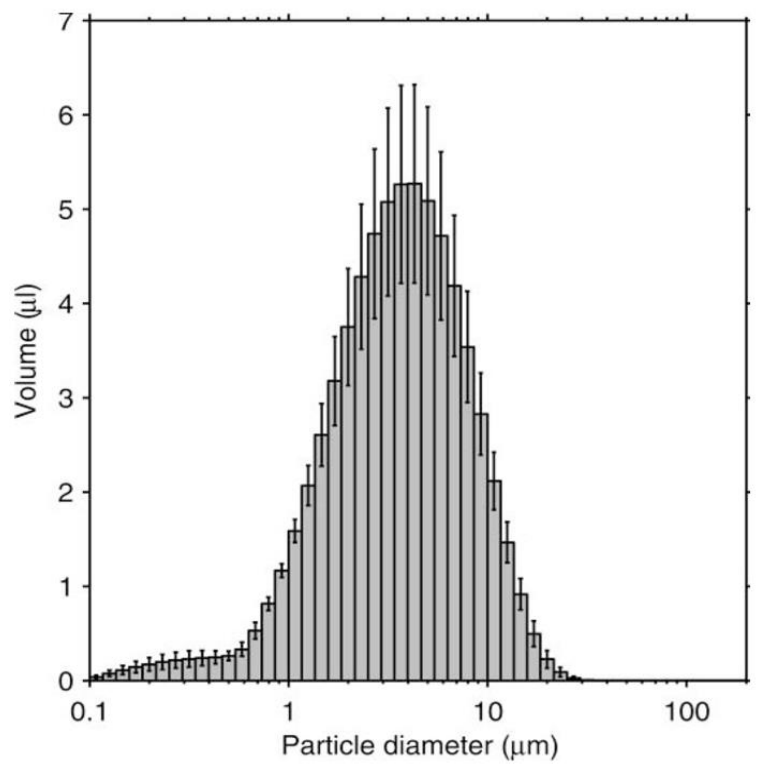

The next step in gathering information was to learn about the methods of filtration found in N95 respirators that were used by healthcare workers. N95 respirators were originally developed by the 3M Company to limit the spread of both inhaled and exhaled aerosols and to also protect workers from inhaling dust and other construction by-products. In $19853 \mathrm{M}$ was issued a patent titled "MOLDED FIBROUS FILTRATION PRODUCTS" (US Patent No. 4,536, 440). ${ }^{12}$ The patent abstract disclosed "Molded filtration products, such as disposable face masks, are prepared by assembling at least one fibrous shaping layer and one fibrous filtration layer in face-to-face contact and subjecting the assembly to heat and molding pressure. Preferably the assembly comprises two shaping layers, one on each side of the filtration layer."'The patent included two drawings 
that disclosed the structure of the disposable face mask. As shown in FIG. 2 of the " 440 patent, the mask body 11 preferably comprises three layers, a first (upstream) shaping layer 14, a filtration layer 15, and a second shaping layer 16. Claim 2 of the " 440 patent claims " A molded filtration product of claim 1 in which the filtration layer comprises melt-blown fibers having an average diameter of no more than about 10 micrometers". (emphases added)

Figure 3: Drawings from U.S. Patent No. 4,536, 440
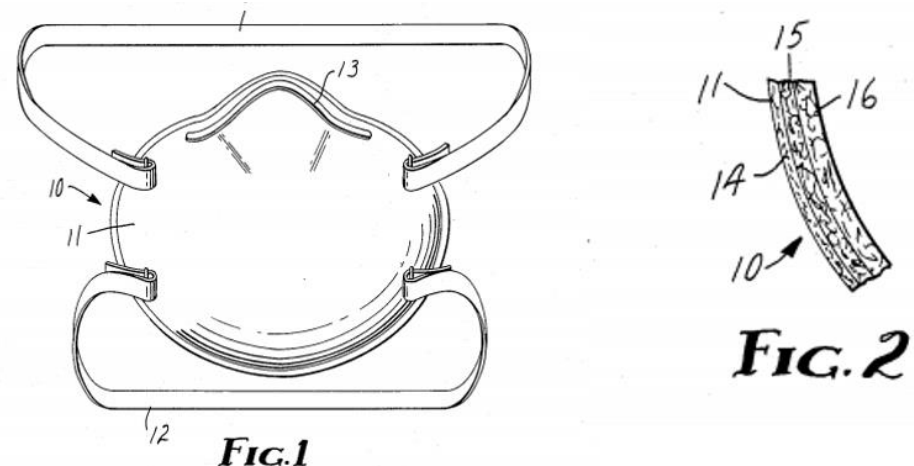

Melt blown fibers are ultra-fine fibers (finer than a human hair) and, as such, when they are formed into a fibrous textile batt they have a relatively high amount of particulate trapping fiber-to-fiber contacts. As such, they are commonly used in air filtration products. In 1994, 3M was issued a patent titled "MOLDED MULTIPLE-LAYER FACE MASK" (U.S. Patent No. 5,374,458)13 This patent disclosed improvements to those disclosed in the " 440 patent and in particular disclosed a middle layer 20 comprising an electrically charged melt blown polypropylene microfiber web.

Figure 4: Drawing from U.S. Patent No. 5,374,458

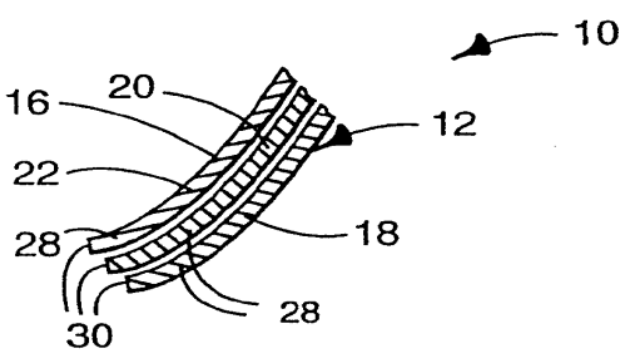

Fig. 2

Subsequently, 3M was issued a patent titled "COMPOSITION USEFUL FOR MAKING ELECTRET FIBERS" (US Patent No, 5,919,847). ${ }^{14}$ The patent disclosed in the BACKGROUND OF THE INVENTION "The aerosol filtration efficiency of nonwoven fibrous webs can be improved by imparting an electrical charge to the fibers, forming an electret material." (emphasis added)

3M continued improvement of face masks and in 2006 they were issued a patent titled "FIBROUS FILTRATION FACE MASK" (U.S. Patent No. 7,131,442). ${ }^{15}$ This patent disclosed expressly that "Fibrous-filtration-face-masks are well known in the respiratory art. Such face masks are worn over the breathing passages of a person and typically serve at least one of two purposes: (1) to prevent impurities or contaminants from entering the wearer's breathing tract; and (2) to protect others from being exposed to bacteria and other contaminants exhaled by the 
wearer. In the first situation, the mask would be worn in an environment where the air contains particles harmful to the wearer. In the second situation, the mask would be worn, for example, in an operating room to protect a patient from infection."

All of the 3M face mask patents disclosed that the items claimed in those patents are made from melt blown fibrous webs and the latter patent included a further disclosure that the addition of electrically charged fibers would enhance filtration. In view of that, it became obvious that a protective face mask that could be used in place of an N95 respirator should have a filtration layer made from melt blown electrically charged fibers. As noted above, the CDC still does not recommend that the general public wear N95 respirators to protect themselves from respiratory diseases, including coronavirus. Those are still considered critical supplies that must continue to be reserved for healthcare workers.

Figure 5: 3M N95 melt blown fibrous web

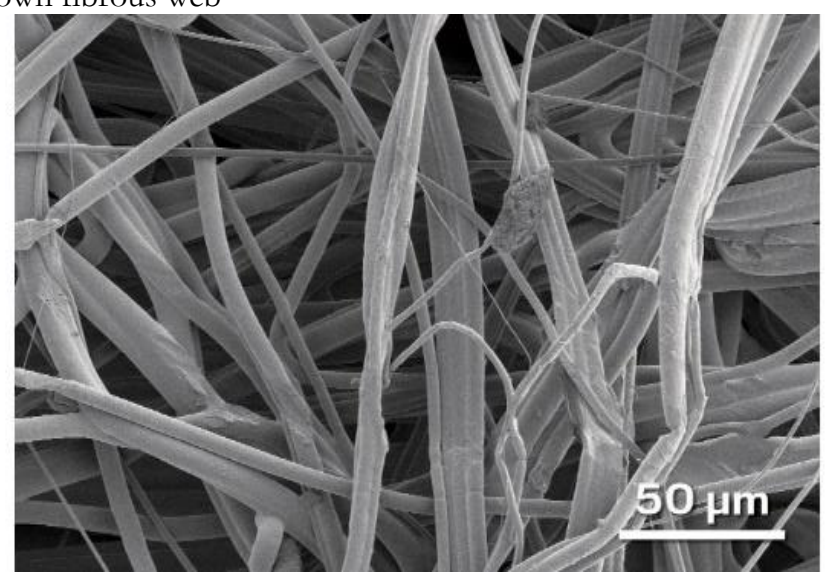

The second step in "Clarifying and formulating the problem" is to conduct a stakeholder analysis. This was relatively straightforward. The CDC reported that by May 31, 2020 the incidence of COVID-19 infections was beginning to grow exponentially and the stakeholders were US citizens being exposed to the virus. ${ }^{16}$ The third step in "Clarifying and formulating the problem" is operational research. This involves determining limitations such as money, time and resources. The goal was to solve the problem using readily available inexpensive materials and have a complete design that the author or others could easily assemble using simple tools such a scissors and rulers. The fourth step in "Clarifying and formulating the problem" is hazard analysis. The primary hazard was the potential toxicity of the materials used in the final mask design. The author determined that materials used for the face masks, including the filter materials, should be common materials that are widely recognized as non-toxic since they were either cotton or polypropylene fibers. The last step in "Clarifying and formulating the problem" is specification creation. The primary specification was a filtration capability similar to that of an N95 respirator.

\section{Solving the Problem}

There are three developmental steps to solving the problem; creative design, conceptual design and finally prototype design. Creative design began with developing a highly protective face mask with readily available materials that was comparable to an N95 respirator and involved two-steps. The first step was identifying a readily available and efficacious filter material along with a comfortable and tight-fitting fabric encasement. The second step involved designing a way to combine and produce protective face masks with those materials. 
Filter Material

The 3M “AIR FILTER WITH SORBENT PARTICLES" ("532 patent") patent issued in 2017 discloses FILTRETETM brand furnace filters comprising a melt-blown non-woven fabric with electrostatically charged non-toxic polypropylene fibers (just as with an N95 respirator) with sorbent materials in the filter. ${ }^{17}$ Further, the 532 patent disclosed that the sorbent materials include viricides which have the capacity to or tend to destroy or inactivate viruses.

Figure 6: 3M FILTRETETM filter melt blown fibrous web

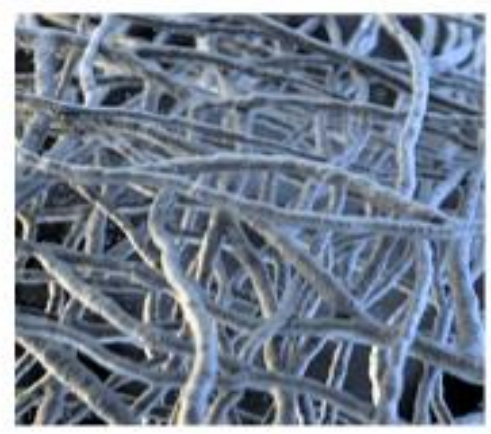

Figure 7: Drawings from U.S. Patent No. 9,539,532 which disclose the structure of the filter material and how the sorbent materials 14 are added to the melt blown non-woven fibrous structure

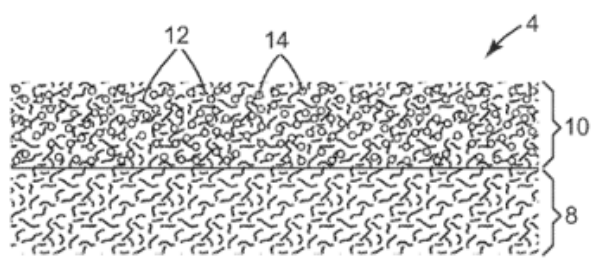

Fig. 3

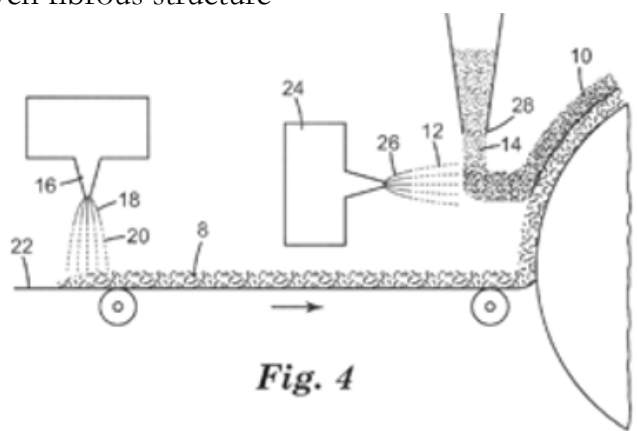

The melt-blown electrostatically charged filter fabric is subsequently contructed into a furnace filter by pleating it. Once pleated the filter material is fastened onto a cardboard frame. This is illustrated in Fig. 1 and Fig. 2 of the '532 patent.

Figure 8: Drawings from U.S. Patent No. 9,539,532 which show the structure of a 3M FILTRETE ${ }^{\text {TM }}$ HVAC filter

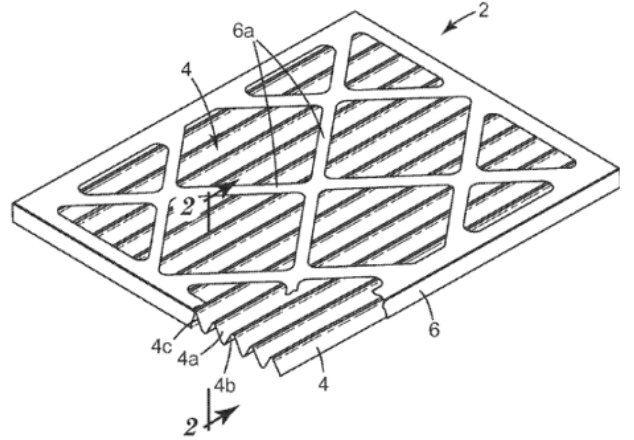

Fig. 1

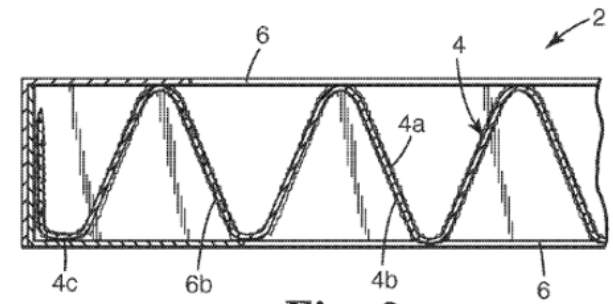

Fig. 2 
The fabric in the furnace filter can be easily harvested from the commercially available FILTRETETM products by cutting away the cardboard frame and removing the filter fabric.

In a recent article in the American Society of Heating, Refrigerating and Air-Conditioning Engineers Journal it was suggested that to mitigate spread of COVID-19 in a building the HVAC filters should be rated to at least a Minimum Efficiency Reporting Value (MERV) of $13 .{ }^{18} \mathrm{~A}$ readily available MERV 13 FILTRETE ${ }^{\text {TM }}$ filter is the MPR 1900. 3M reports the following particle size efficiency (PSE) $\%$ of the HVAC filter.

Table 1: Particle Size Efficiency of a MERV 13 FILTRETETM HVAC filter

\begin{tabular}{|c|c|c|c|}
\hline Particle Size Efficiency & $62 \%$ & $87 \%$ & $95 \%$ \\
\hline Microns, $\mu \mathrm{m}$ & $0.3-1.0$ & $1.0-3.0$ & $3.0-10.0$ \\
\hline
\end{tabular}

Recognizing that the volume median dimeter of a human cough aerosol is $3.39 \mu \mathrm{m}$, a FILTRETETM MPR 1900 was chosen for the filter material for the newly designed face masks since this would result in a 95\% particle size efficiency which is comparable to an N95 respirator. The next step in "Solving the Problem" is conceptual design. Once it was determined that melt blown non-woven fibrous web similar to that found in a FILTRETE MERV 13 filter would provide effective particle filtration a final design consisting of combining that material with a common cotton jersey knit T-Shirt would make an effective protective face mask. Several designs that incorporated that filter material and fabric encasement were constructed. Constructions that enhanced tight fit while retaining wearer comfort were investigated. Further, the robustness and durability of the mask was also considered.

\section{Fabric Encasement}

While a jersey knit fabric used alone would not provide enough filtering capability to mitigate and protect against being exposed to aerosols containing COVID-19 virus particles, a filter material consisting of FILTRETETM MPR 1900 non-woven fabric combined with a comfortable jersey knit fabric would offer protection and mitigate community spread of the virus. Jersey knit T-shirts were purchased and cut into dimensions discussed below.

The next step in "Solving the Problem" was creating a prototype design. Jersey knit fabric rectangles measuring 7" by 10 " were cut from readily available unused T-shirts. The fabric rectangles were then folded so that the two-layer fabric was now 7" by 5". Metal grommets were then pressed into the folded fabric along the edges. Elastic bands, to secure the face mask to the wearer, were then tied to the grommets. Filter material measuring $4 \frac{1 / 2}{2}$ " by 5 " was harvested from FILTRETETM MPR 1900 HVAC filters. The filter material was then sandwiched into the middle of the folded knit jersey fabric. Below is a drawing of the constructed mask and a picture of the prototype face mask. 
Figure 9: Construction of the newly designed protective face mask

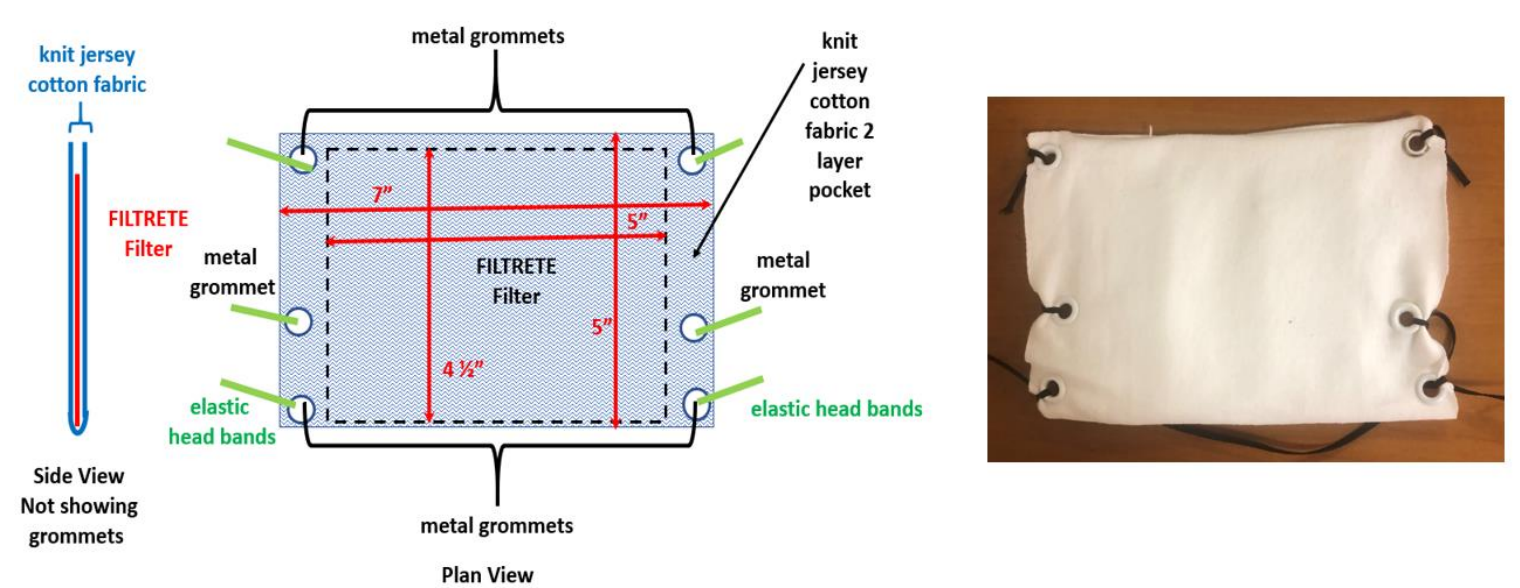

\section{Verification}

The final step in the Design Thinking Process is Verification. During normal times, where laboratory testing facilities are readily available to test the viricidal efficacy and fit testing of the newly developed masks it, would be an important part of the verification final step in the Design Thinking process. Nonetheless, the design was shared with the Dean of the Katz School of Medicine at Temple University and he instructed the Center for Urban Bioethics at the medical school to adopt the design and assemble a group of volunteers, primarily medical students, to produce many thousands of the protective masks. Their goal was to produce the masks and distribute them to residents of the North Philadelphia community to mitigate the spread of COVID-19. As of the fall of 2020, this initiative has produced and distributed about 10,000 face masks.

As effective face coverings are considered a critical means for mitigating the spread of COVID-19, many manufacturers are now designing and selling protective face masks that contain filters. However, their comparative efficacy is largely unknown at this time.

For example, recently a highly effective and readily commercially available protective face mask was identified by the author. (HALOmask ${ }^{\text {TM}}$ ). ${ }^{19}$ It comprises two layers of knitted fabric with an electro spun melt blown non-woven nanofiber filter. ${ }^{20}$ The filter is placed between the two layers of knitted fabric. In June 2020, the manufacturer of HALOmask contracted with Nelson Labs ${ }^{21}$ to determine the particulate filter efficiency of the nanofiber melt blown fibrous webs using ASTM Standard F2299 "Standard Test Method for Determining the Initial Efficiency of Materials Used in Medical Face Masks to Penetration by Particulates Using Latex Spheres". ${ }^{22}$ This test method establishes procedures for measuring the initial particle filtration efficiency of materials used in medical face masks using monodispersed aerosols. The method measures the initial filtration efficiency of materials used in medical face masks by sampling representative volumes of the upstream and downstream latex aerosol concentrations in a controlled airflow chamber. 
Figure 10. HALOmask with electro spun melt blown fibrous web
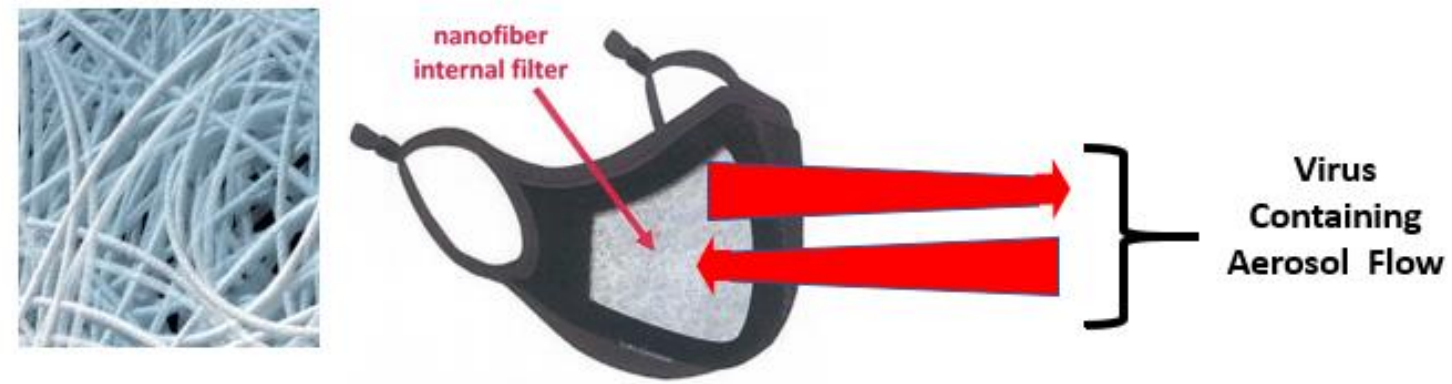

Table 2. Particle size filter efficiency of HALOmask ${ }^{\text {TM }}$ filters measured in accordance with ASTM Standard Test Method F2299

\begin{tabular}{|c|c|c|c|c|}
\hline $\begin{array}{c}\text { Particulate Filtration } \\
\text { Efficiency }\end{array}$ & $99.9 \%$ & $97.5 \%$ & $97.5 \%$ & $98.0 \%$ \\
\hline $\begin{array}{c}\text { Particle Size } \\
\text { Microns, } \mu \mathrm{m}\end{array}$ & 0.1 & 0.3 & 0.5 & 1.0 \\
\hline
\end{tabular}

Recently Honeywell recently started offering a commercially available Dual-Layer Face Cover that includes a replaceable filter. Their web site indicates that the filter has a particulate filter efficiency (PFE) of $\geq 97 \%$ for $0.1 \mu \mathrm{m}$ sized particles. At this time, Honeywell has not indicated the method that was used to determine this PFE measurement. ${ }^{23}$

On October 4, 2020 the CDC posted "Scientific Brief: SARS-CoV-2 and Potential Airborne Transmission". ${ }^{24}$ The brief stated "The principal mode by which people are infected with SARSCoV-2 (the virus that causes COVID-19) is through exposure to respiratory droplets carrying infectious virus. Respiratory droplets are produced during exhalation (e.g., breathing, speaking, singing, coughing, sneezing) and span a wide spectrum of sizes that may be divided into two basic categories based on how long they can remain suspended in the air'. (emphasis added)

On October 23, 2020, researchers at the Institute for Health Metrics and Evaluation at the University of Washington published online that they found "that achieving universal mask use (95\% mask use in public) could be sufficient to ameliorate the worst effects of epidemic resurgences in many states. Universal mask use could save an additional 129,574 (85,284-170,867) lives from September 22, 2020 through the end of February 2021, or an additional 95,814 (60,731-133,077) lives assuming a lesser adoption of mask wearing (85\%), when compared to the reference scenario." 25 On November 10, 2020, the CDC posted online an update titled "Scientific Brief: Community Use of Cloth Masks to Control the Spread of SARS-CoV-2". 26 This update addressed filtration for personal protection. The update states "Studies demonstrate that cloth mask materials can also reduce wearers' exposure to infectious droplets through filtration, including filtration of fine droplets and particles less than 10 microns." (emphasis added) With regard to filter materials the update states "Some materials (e.g., polypropylene) may enhance filtering effectiveness by generating triboelectric charge (a form of static electricity) that enhances capture of charged particles while others (e.g., silk.) may help repel moist droplets and reduce fabric wetting and thus maintain breathability and comfort." 


\section{Conclusion}

While early on in the pandemic the public was discouraged from wearing face masks since government officials wanted to preserve the limited availability to healthcare workers, that discouragement was soon changed when it was recognized how widespread the pandemic had become. For the most part, the only face masks that were available to the public comprised fairly ineffective $100 \%$ woven or knitted cloth. The author, who leads the undergraduate engineering curricular initiative to embed design thinking across the curriculum, utilized design thinking to design a new mask. Recognizing that readily available effective filter materials were available, a more robust face mask that would not only mitigate community spread but might even protect the wearer from infection from the virus, a protective face mask was developed. Eventually commercial manufacturers developed face masks that contained effective filters, which provide an important tool to further mitigate the spread of the virus. The author's future plans are to investigate the protective capacity of additional commercial face masks as they come into the market. While eventually vaccines will be approved and administered to mitigate the spread of COVID-19 the remaining studies will help prepare the public for mask mitigation of future pandemic respiratory viruses.

\section{Filter and Mask Disclaimers}

\section{M FILTRETETM}

"Our filters are designed to be used in HVAC systems, and the filter media bas not been tested to be used as a face mask for respiratory protection. Altering any of our $3 M$ Filtrete ${ }^{\mathrm{TM}}$ Air Filters is not recommended or supported by $3 M$ or the Filtrete ${ }^{\mathrm{TM}}$ Brand.' 27

HALOLIFETM

"Because HALOmask is not categorized as a medical device, certification by the FDA and NIOSH is not required. Medical mask certifications only apply to face masks that are single use and disposable." "Filters are currently in process of being certified for USA, EU, AU/NZ, Korea, Vietnam and other regions." 28

HONEYWELL FACE COVERS

"NOT FDA APPROVED: Not Intended for Medical Use; Not Tested Against COVID-19...Product in development.'29

\section{Disclosures and Conflicts of Interest}

The author discloses no conflicts of interest.

\section{Funding Sources}

The author's research was not sponsored by any outside entities and has received no compensation from either the $3 \mathrm{M}$ corporation (FILTRETE ${ }^{\text {TM }}$ ), HALOLIFE (HALOmask) or Honeywell. His only source of funding was his regular salary at Temple University College of Engineering.

\section{Acknowledgments}

The author acknowledges the efforts of the staff of the Center for Urban Bioethics at the Larry Katz School of Medicine for producing and distributing the face masks that were developed. 
The author acknowledges Blade Kotelly, Senior Lecturer at the MIT Engineering Leadership Program who taught me the concepts of Design Thinking and my late doctoral thesis advisor, Professor Stanley Backer at MIT, who guided me on my research in area of textile/mechanical engineering over 50 years ago.

The author also acknowledges the inspiration for this mask project from the late Steven Frumkin, Dean of the Jay Baker School of Business and Technology at the Fashion Institute of Technology in New York City. Dean Frumkin succumbed to the COVID-19 virus during the summer of 2020.

\section{References}

1. Strasser, BJ, Schlich, T., A history of the medical mask and the rise of the throwaway culture. THE LANCET. 2020; 10243: 19-20

2. Soucheray S., Coroner: First US COVID-19 death occurred in early February, U.Minnesota CIDRAP, Available from https://www.cidrap.umn.edu/news-perspective/2020/04/coroner-firstus-CoVid-19-death-occurred-early-february

3. Brewster, J., Is Trump Right That Fauci Discouraged Wearing Masks? Yes—But Early On And Not For Long. Forbes. 2020 Oct 20 Available from https://www.forbes.com/sites/jackbrewster/2020/10/20/is-trump-right-that-fauci-discouragedwearing-masks/\#705f12364969

4. Dr. Anthony Fauci talks with Dr. Jon LaPook about Covid-19. March 2020, CBS 60 MINUTES Available from https://youtu.be/PRa6t_e7dgI

5. Use of Cloth Face Coverings to Help Slow the Spread of COVID-19. CDC, Available from https://web.archive.org/web/20200413003205/https://www.cdc.gov/coronavirus/2019ncov/prevent-getting-sick/diy-cloth-face-coverings.html

6. Adams, J., How to Make Your Own Face Coverings, US Surgeon General Office, Available from https://www.youtube.com/watch?v=tPx1yqvJgf4

7. Davies A, Thompson KA, Giri K, Kafatos G, Walker J, Bennett A. Testing the efficacy of homemade masks: would they protect in an influenza pandemic? Disaster Med Public Health Prep. 2013 Aug; 7(4):413-8

8. Bourouiba, L., Turbulent Gas Clouds and Respiratory Pathogen Emissions: Potential Implications for Reducing Transmission of COVID-19. JAMA. 2020;323(18):1837-1838

9. Kotelly, B., The 10-Steps to Design Thinking, (2019). MIT Insights. Available from https://www.machinedesign.com/community/article/21837470/the-10-steps-to-design-thinking

10. https://www.fda.gov/medical-devices/personal-protective-equipment-infection-control/n95respirators-surgical-masks-and-face-masks

11. Lindsley WG, Reynolds JS, Szalajda JV, Noti JD, Beezhold DH. A Cough Aerosol Simulator for the Study of Disease Transmission by Human Cough-Generated Aerosols. Aerosol Sci Technol. 2013;47(8):937-944.

12. Berg, HJ, inventor; $3 \mathrm{M}$ Company, assignee. Molded fibrous filtration products. United States patent US 4,536,440, 1985 Aug 20.

13. Burgio, PA, inventor; $3 \mathrm{M}$ Company, assignee. Molded, multiple-layer face mask. United States patent 5,374,458, 1994 Dec 20.

14. Rousseau, AD et al., inventor; $3 \mathrm{M}$ Company, assignee. Composition useful for making electret fibers. United States patent 5,919,847. 1999 Jul 6.

15. Kronzer, JP. et al., inventor; 3M Company, assignee. Fibrous filtration face mask. United States patent 7,131,442. 2006 Nov 7.

16. Salvatore PP, Sula E, Coyle JP, et al. Recent Increase in COVID-19 Cases Reported Among Adults Aged 18-22 Years - United States, May 31-September 5, 2020. MMWR Morb Mortal Wkly Rep 2020;69:1419-1424.

17. Fox, AR et al., inventor; $3 \mathrm{M}$ Company, assignee. Air filter with sorbent particles United States patent 9,539,532. 2017 Jan 10. 
18. Schoen, LJ., Guidance for Building Operations During the COVID-19 Pandemic ASHRAE Journal, May 2020. $72-74$

19. HALOLife ${ }^{\mathrm{TM}}$ web site. Available at https://halolife.io/

20. Karabulut, F., The case for electrospun nanofibers in face masks, Advanced Textile Source 2020 Available at https://advancedtextilessource.com/2020/08/24/the-case-for-electrospun-nanofibersin-face-masks/

21. Nelson Labs website. Available at https://www.nelsonlabs.com/our-company/

22. ASTM Standard F2299, 2017, "Standard Test Method for Determining the Initial Efficiency of Materials Used in Medical Face Masks to Penetration by Particulates Using Latex Spheres", ASTM International, West Conshohocken, PA, 2003

23. Honeywell Face Covers Available at https://ppe.honeywell.com/collections/facecovers/products/honeywell-3d-knit-face-mask

24. CDC Scientific Brief: SARS-CoV-2 and Potential Airborne Transmission, (October 4, 2020)

25. Reiner, RC., Barber, RM Collins, JK. et al. Modeling COVID-19 scenarios for the United States. Nat Med (2020)

26. CDC Scientific Brief: Community Use of Cloth Masks to Control the Spread of SARS-CoV-2, (November 10, 2020)

27. Coronavirus and Important Things to Know About Airborne Particles, March 23, 2020, Available at https://www.filtrete.com/3M/en_US/filtrete/home-tips/full-story/ / coronavirus-andimportant-things-to-know-about-airborne-particles/?storyid=d69e7735-c02c-46d2-9c8aae23372934ac

28. HALOmask ${ }^{\mathrm{TM}}$ FAQ Available at https://halolife.io/pages/faq

29. Honeywell Face Covers Available at https:/ppe.honeywell.com/collections/facecovers/products/honeywell-3d-knit-face-mask

\section{About the Author}

David Brookstein, Sc.D. is Senior Associate Dean and Professor of Mechanical Engineering in the College of Engineering at Temple University. He has an undergraduate degree in textile engineering from Georgia Tech, an MS degree in textile technology and a Doctor of Science degree in the field of Mechanical Engineering from MIT. In addition to serving as an academic, he worked for 14 years as an industrial researcher in the field of textile engineering. He was the Principal Investigator for an eightyear project (Laboratory for Engineered Human Protection) sponsored by the US Department of Defense. He is a Fellow of the American Society of Mechanical Engineers and a Fellow of the Textile Institute (UK). He received the Harold DeWitt Smith Award from the ASTM for Outstanding Achievement in the Science of Textile Fiber Utilization. He is listed as an inventor on 13 US patents in the field of textile/mechanical engineering and bioengineering. 